\title{
Effect of calcium intake on urinary oxalate excretion in calcium stone-forming patients
}

J.L. Nishiura, L.A. Martini, C.O.G. Mendonça, N. Schor and I.P. Heilberg

\author{
Disciplina de Nefrologia, Universidade Federal de São Paulo, \\ São Paulo, SP, Brasil
}

\section{Correspondence \\ I.P. Heilberg \\ Disciplina de Nefrologia, UNIFESP \\ Rua Botucatu, 740 \\ 04023-900 São Paulo, SP \\ Brasil \\ Fax: +55-11-5573-9652 \\ E-mail: ipheilberg@ nefro.epm.br}

Research supported by FAPESP (No. 97/07033-7) and Fundação O swaldo Ramos.

Received October 9, 2001

Accepted April 1, 2002

\section{Abstract}

Dietary calcium lowers the risk of nephrolithiasis due to a decreased absorption of dietary oxalate that is bound by intestinal calcium. The aim of the present study was to evaluate oxaluria in normocalciuric and hypercalciuric lithiasic patients under different calcium intake. Fifty patients ( 26 females and 24 males, $41 \pm 10$ years old), whose 4 day dietary records revealed a regular low calcium intake $(\leq 500 \mathrm{mg}$ / day), received an oral calcium load ( $1 \mathrm{~g} /$ day) for 7 days. A 24-h urine was obtained before and after load and according to the calciuria under both diets, patients were considered as normocalciuric $(\mathrm{NC}, \mathrm{N}=15)$, diet-dependent hypercalciuric (DDHC, $\mathrm{N}=9$ ) or diet-independent hypercalciuric (DIHC, $\mathrm{N}=26$ ). On regular diet, mean oxaluria was 30 $\pm 14 \mathrm{mg} / 24 \mathrm{~h}$ for all patients. The 7-day calcium load induced a significant decrease in mean oxaluria compared to the regular diet in $\mathrm{NC}$ and DIHC $(20 \pm 12$ vs $26 \pm 7$ and $27 \pm 18$ vs $32 \pm 15 \mathrm{mg} / 24 \mathrm{~h}$, respectively, $\mathrm{P}<0.05)$ but not in DDHC patients $(22 \pm 10$ vs $23 \pm 5 \mathrm{mg} /$ $24 \mathrm{~h}$ ). The lack of an oxalate decrease among DDHC patients after the calcium load might have been due to higher calcium absorption under higher calcium supply, with a consequent lower amount of calcium left in the intestine to bind with oxalate. These data suggest that a longlasting regular calcium consumption $<500 \mathrm{mg}$ was not associated with high oxaluria and that a subpopulation of hypercalciuric patients who presented a higher intestinal calcium absorption (DDHC) tended to hyperabsorb oxalate as well, so that oxaluria did not change under different calcium intake.

\section{Introduction}

The prevalence of nephrolithiasis may be affected by genetic, environmental and nutritional factors (1). In the past, calcium restriction became a very popular recommendation based on the high prevalence (about $50 \%$ ) of idiopathic hypercalciuria in calcium stone-forming patients (2), its impact on cal-

\section{Key words}

- Calcium

- Hypercalciuria

- Hyperoxaluria

- Kidney stones

- Oxalate

..................... cium oxalate and phosphate saturation (3), and also because of the contribution of calcium intake to hypercalciuria. Indeed, idiopathic hypercalciuria may be ascribed to an increased intestinal calcium absorption, increased bone resorption and decreased renal tubular calcium reabsorption (4). However, there is no evidence that a reduction in dietary calcium intake prevents stone recur- 
rence. A large prospective dietary survey of healthy men showed an increase rather than a decrease in stone disease incidence when dietary calcium intake was below $516 \mathrm{mg} /$ day (5), probably due to an increased free oxalate concentration in the intestinal lumen owing to less calcium to bind with. As urine normally contains much less oxalate than calcium, small increases in urinary oxalate concentration will have a relatively greater effect on calcium oxalate supersaturation than great changes in calcium concentration.

In a previous study (6), we observed that Brazilian calcium stone-forming and healthy subjects have a low calcium intake, not higher than $500 \mathrm{mg} /$ day, reaching only 30 to $50 \%$ of the recommended dietary allowances, as part of their dietary habit. The aim of the present study was to evaluate the urinary excretion of oxalate in calcium stone-forming patients who chronically consumed a low calcium diet, and to examine the effects of an increase in calcium intake on urinary oxalate excretion in normocalciuric and hypercalciuric calcium stone-forming patients.

\section{Subjects and Methods}

\section{Subjects}

Sixty-five calcium stone-forming patients with normal renal function were referred to the Renal Lithiasis Unit of the Nephrology Division, Universidade Federal de São Paulo, São Paulo, SP, Brazil, because of stone formation. The diagnosis of stone formation was based on a history of colic episodes with expulsion of stones (spontaneous or after shock wave lithotripsy) and previous or present radiographic evidence of radiopaque stones. Patients with diseases affecting calcium metabolism (primary hyperparathyroidism, hyperthyroidism, acromegaly, sarcoidosis, diabetes, neoplasias, etc.) or taking drugs which could not be withdrawn during the protocol (corticosteroids, inhibitors of prostaglandin synthesis, diuretics, oral con- traceptives, anticonvulsants, etc.) were not included in the study. After an initial clinical evaluation, all of them were submitted to a 4day dietary record. Fifty of the 65 calcium stone-forming patients whose dietary records disclosed a regular calcium intake below $500 \mathrm{mg} /$ day were included in the study. Written informed consent was obtained from all patients and the study was approved by the Ethics Committee of the Universidade Federal de São Paulo.

Twenty-two healthy volunteers ( 9 males and 13 females) who had never formed a kidney stone underwent a 24-h urinary oxalate excretion determination as controls. A 4-day dietary assessment could not be obtained for these controls.

\section{Methods}

Baseline dietary record. During the baseline period, dietary habit was assessed through a 4-day dietary record. Subjects were instructed to keep a daily record describing the amount of each food consumed and not modifying their habitual diet. After the records were received, the same nutritionist evaluated the daily food record during an interview. Calcium, oxalate and other nutrient intakes were calculated using a computer program (6). For better accuracy, $\mathrm{NaCl}$ intake was calculated based on the levels of urinary sodium rather than on the dietary record.

Baseline urinary parameters. A 24-h urine sample was collected on the 4th day of the dietary record to determine calcium, sodium, potassium, creatinine and oxalate. On a different occasion, a 12-h fasting urine sample was obtained from 18 of the 35 hypercalciuric patients for determination of urinary fasting $\mathrm{Ca} / \mathrm{Cr}$ ratio.

Chronic oral calcium load. The chronic oral calcium load consisted of $1 \mathrm{~g}$ of calcium (500 mg bid) administered orally at mealtime for 7 days, in addition to their regular diet with the timing of calcium load identical 
for all groups. During this period, patients were instructed by the nutritionist to maintain their regular intake of calcium and oxalate to match the intake reported in the first dietary record.

Post-load dietary record. A second 4day dietary record was then obtained from every patient to ensure that the calcium and oxalate intakes of both records were similar, with the calcium supplements being the single difference between the two periods. Subjects who had modified their diet were not included in the study.

Post-load urinary parameters. A 24-h urine sample was collected on the 4th day to determine calcium and oxalate.

\section{Laboratory analysis}

Urinary oxalate was measured by an enzymatic method (7) based on the oxidation of oxalate by oxalate oxidase followed by measurement of hydrogen peroxide produced during the reaction by a peroxidase-catalyzed reaction using the Sigma Oxalate Diagnostic kit (Sigma, St. Louis, MO, USA). The urine samples were acidified below $\mathrm{pH}$ 2.0. The normal limit of oxalate was considered to be $<44 \mathrm{mg} / 24 \mathrm{~h}$. Calcium was determined by atomic absorption spectrophotometry (Perkin-Elmer Atomic Spectrophotometer 290B, Norwalk, CT, USA). Creatinine was measured by the alkaline picrate Jaffe reaction (8) and uric acid by the uricase method (9). Urinary citrate was determined by the citrate-lyase enzymatic reaction (10). Sodium and potassium were measured by flame emission spectrophotometry.

\section{Statistical analysis}

Nonparametric tests were used (KruskalWallis complemented by the Dunn test) to compare the results of all groups. The Wilcoxon test was used to compare results obtained after calcium load versus regular diet in the same group. Statistical significance was defined as $\mathrm{P}<0.05$.

\section{Results}

Fifty calcium stone-forming patients, 26 females and 24 males, $41 \pm 10$ years old, were evaluated. They presented significantly higher urinary calcium and oxalate levels when compared to 22 healthy subjects (236 \pm 103 vs $181 \pm 58$ and $30 \pm 14$ vs $22 \pm 11 \mathrm{mg} /$ $24 \mathrm{~h}, \mathrm{P}<0.05$, respectively). Mean urinary parameters obtained under the regular diet and after the calcium load are shown in Table 1. Urinary calcium, sodium, potassium and creatinine levels after calcium load did not differ from those obtained during the regular diet. Conversely, urinary oxalate was significantly decreased after the calcium load $(25 \pm 15$ vs $30 \pm 14 \mathrm{mg} / 24 \mathrm{~h}, \mathrm{P}<0.05)$.

The 50 calcium stone-forming subjects were classified according to the levels of 24-h urinary calcium on their regular diet and after the calcium load. Patients who presented urinary calcium excretion $\leq 4 \mathrm{mg}$ $\mathrm{kg}^{-1} 24 \mathrm{~h}^{-1}$ on their regular diet and after a calcium load were classified as normocalciuric $(\mathrm{NC}, \mathrm{N}=15)$. Patients with urinary calcium excretion $\leq 4 \mathrm{mg} \mathrm{kg}^{-1} 24 \mathrm{~h}^{-1}$ on their usual diet and $>4 \mathrm{mg} \mathrm{kg}^{-1} 24 \mathrm{~h}^{-1}$ following the calcium load were classified as diet-dependent hypercalciuric (DDHC, $\mathrm{N}=9$ ) and those presenting urinary calcium excretion $\geq 4 \mathrm{mg}$ $\mathrm{kg}^{-1} 24 \mathrm{~h}^{-1}$ on their low-calcium regular diet (calcium intake $\leq 500 \mathrm{mg} /$ day) were classified as diet-independent hypercalciuric (DIHC, $\mathrm{N}=26$ ).

Table 1. Twenty-four-hour urinary parameters under regular diet conditions and after calcium load in 50 calcium stone-forming patients.

\begin{tabular}{llllll}
\hline & $\begin{array}{c}\text { Calcium } \\
(\mathrm{mg} / 24 \mathrm{~h})\end{array}$ & $\begin{array}{c}\text { Oxalate } \\
(\mathrm{mg} / 24 \mathrm{~h})\end{array}$ & $\begin{array}{c}\text { Sodium } \\
(\mathrm{mEq} / 24 \mathrm{~h})\end{array}$ & $\begin{array}{c}\text { Potassium } \\
(\mathrm{mEq} / 24 \mathrm{~h})\end{array}$ & $\begin{array}{c}\text { Creatinine } \\
(\mathrm{mg} / 24 \mathrm{~h})\end{array}$ \\
\hline $\begin{array}{l}\text { Regular diet } \\
\text { After calcium load }\end{array}$ & $236 \pm 103$ & $30 \pm 14$ & $238 \pm 103$ & $50 \pm 20$ & $1322 \pm 351$ \\
& $280 \pm 118^{*}$ & $25 \pm 15^{*}$ & $251 \pm 87$ & $53 \pm 20$ & $1327 \pm 363$ \\
\hline
\end{tabular}

Data are reported as means $\pm S D$.

$* P<0.05$ vs regular diet (Wilcoxon's test). 
Isolated hypocitraturia was detected in $18(36 \%)$ patients, hypocitraturia associated with hyperuricosuria was found in $3(6 \%)$, and hyperuricosuria in 4 patients $(8 \%)$.

Table 2 shows the mean values of calcium, oxalate and sodium chloride intakes obtained from dietary records on the regular diet and after a calcium load. The sodium chloride intake was calculated from 24-h urinary sodium excretion. As a consequence of the supplement given for 7 days, calcium intake was significantly higher compared to the period of regular diet. Oxalate and sodium intake did not change.

Table 3 shows mean urinary calcium and oxalate levels on the regular diet and after

Table 2. Dietary intake of calcium, oxalate and sodium by patients on a regular diet and after calcium load.

\begin{tabular}{lccc}
\hline & NC $(\mathrm{N}=15)$ & DDHC $(\mathrm{N}=9)$ & DIHC (N =26) \\
\hline Regular diet & & & \\
Calcium (mg/day) & $458 \pm 172$ & $460 \pm 223$ & $440 \pm 153$ \\
Oxalate (mg/day) & $54 \pm 30$ & $38 \pm 23$ & $61 \pm 50$ \\
NaCl (g/day) & $13 \pm 5$ & $12 \pm 5$ & $15 \pm 7$ \\
After calcium load & & & \\
Calcium (mg/day) & $1464 \pm 191^{*}$ & $1454 \pm 262^{*}$ & $1536 \pm 209^{*}$ \\
Oxalate (mg/day) & $49 \pm 32$ & $44 \pm 23$ & $62 \pm 58$ \\
NaCl (g/day) & $14 \pm 5$ & $14 \pm 5$ & $15 \pm 5$ \\
\hline
\end{tabular}

Data are reported as means $\pm \mathrm{SD}$. NC $=$ normocalciuric group; $\mathrm{DDHC}=$ diet-dependent hypercalciuric group; $\mathrm{DIHC}=$ diet-independent hypercalciuric group.

$* \mathrm{P}<0.05$ vs regular diet (Wilcoxon's test).

Table 3. Urinary calcium and oxalate excretion ( $\mathrm{mg} / 24 \mathrm{~h}$ ) in normocalciuric (NC), dietdependent (DDHC) and diet-independent (DIHC) hypercalciuric patients.

\begin{tabular}{llll}
\hline & NC $(\mathrm{N}=15)$ & DDHC $(\mathrm{N}=9)$ & DIHC (N =26) \\
\hline $\begin{array}{lll}\text { Urinary calcium } \\
\text { Regular diet }\end{array}$ & $124 \pm 30$ & $189 \pm 30$ & $322 \pm 62^{\#+}$ \\
After calcium load & $164 \pm 44^{*}$ & $386 \pm 90^{*} \#$ & $314 \pm 10^{\#}$ \\
Urinary oxalate & & & \\
Regular diet & $26 \pm 12$ & $23 \pm 5$ & $32 \pm 15^{+}$ \\
After calcium load & $20 \pm 7^{*}$ & $22 \pm 10$ & $27 \pm 18^{*}$ \\
\hline
\end{tabular}

Data are reported as means \pm SD.

$* \mathrm{P}<0.05$ vs regular diet (Wilcoxon' test). ${ }^{\mathrm{P}} \mathrm{P}<0.05$ vs NC; ${ }^{+} \mathrm{P}<0.05$ vs DDHC (KruskalWallis complemented by Dunn test). the calcium load. On the regular diet, the DIHC group presented a significantly higher urinary calcium excretion than $\mathrm{NC}$ and DDHC $(322 \pm 62$ vs $124 \pm 30$ and $189 \pm 30$ $\mathrm{mg} / 24 \mathrm{~h}$, respectively). When corrected for body weight, urinary calcium continued to be significantly higher in the DIHC group than in the $\mathrm{NC}$ and DDHC groups $(4.8 \pm 0.7$ vs $1.8 \pm 0.5$ and $\left.2.9 \pm 0.8 \mathrm{mg} \mathrm{kg}^{-1} 24 \mathrm{~h}^{-1}\right)$ but the mean weight was similar for the NC, DDHC and DIHC groups $(67 \pm 10,68 \pm 18$ and $67 \pm 13 \mathrm{~kg}$, respectively) (data not shown). On a regular diet, the urinary oxalate excretion was significantly higher in DIHC than DDHC ( $32 \pm 15$ vs $23 \pm 5 \mathrm{mg} / 24$ h). In the post-load period, urinary calcium was significantly higher in both hypercalciuric groups (DDHC and DIHC) when compared to the NC group, who remained normocalciuric (386 \pm 90 and $314 \pm 10$ vs $164 \pm$ $44 \mathrm{mg} / 24 \mathrm{~h}$, respectively). Urinary oxalate did not differ between groups.

When compared to the period of regular diet, calcium load induced a significant increase in calciuria in NC (124 \pm 30 vs $164 \pm$ $44 \mathrm{mg} / 24 \mathrm{~h})$ and in DDHC (189 \pm 30 vs 386 $\pm 90 \mathrm{mg} / 24 \mathrm{~h})$ but not in DIHC (322 $\pm 62 \mathrm{vs}$ $314 \pm 10 \mathrm{mg} / 24 \mathrm{~h}$ ).

In 18 patients of the DIHC group submitted to the determination of urinary fasting $\mathrm{Ca} / \mathrm{Cr}$ ratio, 11 patients $(61 \%)$ presented a fasting $\mathrm{Ca} / \mathrm{Cr}$ ratio $\geq 0.11$ and $7(39 \%)<0.11$ (data not shown).

Chronic calcium load induced a significant decrease in mean oxalate excretion in the $\mathrm{NC}$ and DIHC groups $(20 \pm 7$ vs $26 \pm 12$ and $27 \pm 18$ vs $32 \pm 15 \mathrm{mg} / 24 \mathrm{~h}, \mathrm{P}<0.05$, respectively) but not in DDHC ( $22 \pm 10 v s 23$ $\pm 5 \mathrm{mg} / 24 \mathrm{~h}$ ).

Individual values of urinary oxalate within each group are illustrated in Figure 1. Hyperoxaluria (urinary oxalate $>44 \mathrm{mg} / 24$ h) was observed in 2 patients $(13 \%)$ of the $\mathrm{NC}$ group, as shown in Figure 1A, and in 3 patients (11\%) of the DIHC group (Figure 1C). Hyperoxaluria was not observed in the DDHC group. As depicted in Figure 1A, 
$8 \mathrm{NC}(53 \%)$ patients decreased their urinary oxalate after the calcium load. As shown in Figure 1B, 4DDHC (44\%) patients decreased urinary oxalate after the calcium load, while 18 DIHC (69\%) patients did so (Figure 1C). The percentages of patients who presented such a decrease in the NC and DIHC groups were higher (53 and 69\%), albeit not significantly so, when compared to DDHC patients $(44 \%)$.

\section{Discussion}

In the past, since increased calcium intake was considered to be an important risk factor for stone formation, calcium restriction was recommended as an obvious intervention to prevent kidney stones in calcium stone-forming patients suffering from hypercalciuria (11). However, this practice has been questioned due to a large epidemiologic study which reported an increased risk for stone formation in subjects consuming a low calcium diet due to secondary hyperoxaluria (5), although these data had been largely indirect. Furthermore, several investigators have observed that calcium restriction has a deleterious effect on bone in hypercalciuric patients $(12,13)$.

In healthy subjects, Hess et al. (14) observed that an increased calcium intake can totally abolish the hyperoxaluria induced by an oxalate load. However, Bushinsky et al. (15), in an experimental model of genetic hypercalciuric rats, observed that, although urinary calcium proportionally increased with increasing dietary calcium content, a parallel decrease in urinary oxalate did not occur.

The present study was undertaken on the basis of these observations in order to evaluate two important aspects regarding oxaluria in calcium stone-forming patients. First, to determine urinary oxalate levels in patients with habitual low calcium intake, as it is the case in our population (6), and second, to determine whether the postulated inverse relationship between colonic oxalate absorp-

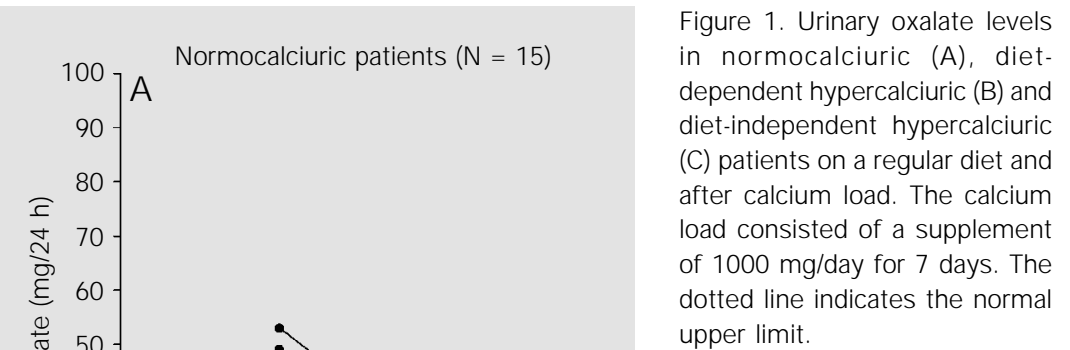

upper limit. 
tion and colonic calcium load is modified when hypercalciuria is present.

In the present series, the entire group of calcium stone-forming patients presented a significantly higher mean oxalate urinary excretion than healthy subjects ( $30 v s 22 \mathrm{mg} /$ $24 \mathrm{~h}$ ) while consuming a diet containing no more than $500 \mathrm{mg} /$ day of calcium. However, this mean oxalate excretion did not differ from the values reported for calcium stoneforming patients with a calcium intake of about $1000 \mathrm{mg} /$ day by our service and others $(16,17)$.

Mild hyperoxaluria is defined by urinary oxalate excretion higher than 40 or $45 \mathrm{mg} /$ day according to some investigators $(18,19)$, or even higher than $33 \mathrm{mg} /$ day according to others $(20,21)$. However, the question of the optimal method for measurement of urinary oxalate is still debated. The large number of analytical procedures used, such as precipitation (22), colorimetric procedures (23), chromatography and enzymatic methods (7) limits comparison of the results of different groups. In the present study, the enzymatic method was chosen because it is simple, inexpensive and in many ways equivalent to other methods.

Of 50 calcium stone-forming patients, 5 $(10 \%)$ presented hyperoxaluria (2 patients belonged to the normocalciuric group and the other 3 to the hypercalciuric group). This incidence of hyperoxaluria is similar to previous reports of 12 to $17 \%$ by others $(19,24)$.

The second purpose of this study was to evaluate oxalate excretion under a higher calcium intake in normocalciuric and hypercalciuric patients, with the latter being classified according to their response to the calcium load as diet-dependent or -independent patients. The increase in urinary calcium after the calcium load, not biased by a higher salt intake $(\mathrm{NaCl}$ intake was similar in both dietary conditions), suggested that 9 hypercalciuric patients were dietary calciumdependent.

The increased urinary calcium under con- ditions of regular low calcium intake and the lack of increase in urinary calcium following the calcium load suggested that a decreased renal tubular reabsorption and/or increased bone resorption might have accounted for the hypercalciuria in the 26 DIHC patients. In $11 / 18(61 \%)$ of these patients a high fasting $\mathrm{Ca} / \mathrm{Cr}$ ratio was detected, indicating a renal leak and/or an increased bone resorption. In the remaining 7 (39\%), a type I absorptive hypercalciuria might have been present.

However, the evaluation of oxalate excretion during the use of both calcium diets revealed different changes according to the influence of calcium intake on calcium excretion.

After increasing calcium intake from 500 to $1500 \mathrm{mg} /$ day through calcium supplements, NC and DIHC patients presented significantly reduced mean urinary oxalate levels compared to baseline ( $20 \pm 7$ vs $26 \pm 12$ and $27 \pm 18$ vs $32 \pm 15 \mathrm{mg} / 24 \mathrm{~h}$, respectively). The dietary calcium-induced variation of about $20 \%$ in mean oxaluria, observed in NC and DIHC patients, agrees well with that reported by other investigators $(11,17)$.

The lack of oxalate decrease in DDHC patients might have been due to a higher calcium absorption under conditions of a higher calcium supply, with a consequent lower amount of calcium in the intestinal lumen to bind oxalate with.

A reduction in calcium intake is deleterious for calcium stone-forming patients whatever their calciuria classification. In DIHC patients, a reduction in calcium intake is undesirable because in addition to not promoting a change in urinary calcium and being deleterious to bone, it induces secondary hyperoxaluria. DDHC patients are not prone to variations in oxaluria but a low calcium diet would probably worsen their bone condition, as previously reported (25-27).

The data indicate that in the present series a long-lasting usual daily calcium con- 
sumption $<500 \mathrm{mg}$ was not associated with high levels of urinary oxalate and that a subpopulation of hypercalciuric patients, i.e., the diet-dependent patients, who present a higher intestinal calcium absorption, tended to hyperabsorb oxalate as well, so that urinary oxalate did not change under different calcium intake conditions.

\section{Acknowledgments}

The authors wish to express their thanks to Dr. Adagmar Andriolo and Silvia R.S. Moreira for technical support.

\section{References}

1. Pak CYC (1998). Kidney stones. Lancet, 351: 1797-1801.

2. Heilberg IP, Martini LA, Draibe SA, Ajzen H, Ramos OL \& Schor N (1996). Sensitivity to calcium intake in calcium stone forming patients. Nephron, 73: 145-153.

3. Coe FL \& Parks J H (1999). Hypercalciuria in the twentieth century. In: Borghi $\mathrm{L}$, Meschi T, Briganti A, Schianchi T \& Novarini A (Editors), Kidney Stones. Proceedings of the 8th European Symposium on Urolithiasis. Editoriale Bios, Parma, Italy, 43-50.

4. Pak CYC (1990). Hyperoxaluric calcium nephrolithiasis. In: Resnick MI \& Pak CYC (Editors), Urolithiasis - A Medical and Surgical Reference. W.B. Saunders, Philadelphia, PA, USA, 65-77.

5. Curhan GC, Willet WC, Rimm EB \& Stampfer MJ (1993). A prospective study of calcium and other nutrients and the risk of symptomatic kidney stones. New England J ournal of Medicine, 328: 833-838.

6. Martini LA, Heilberg IP, Cuppari L, Medeiros FAM, Draibe SA, Ajzen $\mathrm{H} \&$ Schor N (1993). Dietary habits of calcium stone formers. Brazilian J oumal of Medical and Biological Research, 26: 805-812.

7. Hallson PC \& Rose GA (1974). A simplified and rapid enzymatic method for the determination of urinary oxalate. Clinica Chimica Acta, 55: 29-39.

8. McFate RP, Cohn C, Eichelberger $L \&$ Cooper J A (1954). Symposium on azotemia. American J oumal of Clinical Pathology, 24: 511-574.

9. Fossati $P$, Prencipe $L \&$ Berti G (1980). Use of 3,4-dichloro-2-hydroxybenzenesulfonic acid/4-aminophenazone chromogenic system in direct enzyme assay of uric acid in serum and urine. Clinical Chemistry, 26: 227-231.

10. Holt C, Cowley DM \& Chalmers $A H$ (1985). Rapid estimation of urinary citrate by use of a centrifugal analyzer. Clinical
Chemistry, 31: 779-780.

11. Bataille $P$, Charransol $G$, Gregoire I, Daigre J L, Coevoet B, Makdassi R, Pruna A, Locquet J, Sueur J P \& Foumier A (1983). Effect of calcium restriction on renal excretion of oxalate and the probability of stones in the various pathophysiological groups with calcium stones. J oumal of Urology, 130: 218-223.

12. Heilberg IP, Martini LA, Teixeira $\mathrm{SH}$, Szejnfeld VL, Carvalho AB, Lobão R \& Draibe SA (1998). Effect of etidronate treatment on bone mass of male nephrolithiasis patients with idiopathic hypercalciuria and osteopenia. Nephron, 79: 430-437.

13. Weisinger JR (1996). New insights into the pathogenesis of idiopathic hypercalciuria: The role of bone. Kidney International, 49: 1507-1518.

14. Hess B, J ost C, Zipperle L, Takkinen R \& J aeger $P$ (1998). High-calcium intake abolishes hyperoxaluria and reduces urinary crystallization during a 20-fold normal oxalate load in humans. Nephrology, Dialysis, Transplantation, 13: 2241-2247.

15. Bushinsky DA, Kim M, Sessler NE, Nakagawa $Y \&$ Coe FL (1994). Increased urinary saturation and kidney calcium content in genetic hypercalciuric rats. Kidney International, 45: 58-65.

16. Baggio B, Gambaro G, Marchini F, Vincenti M, Ceolotto G, Pessina AC \& Semplicini A (1994). Abnormal erythrocyte and renal frusemide-sensitive sodium transport in idiopathic calcium nephrolithiasis. Clinical Science, 86: 239-243.

17. Messa $P$, Marangella M, Paganin L, Codardini M, Cruciatti A, Turrin D, Filiberto $Z \&$ Mioni G (1997). Different dietary calcium intake and relative supersaturation of calcium oxalate in the urine of patients forming renal stones. Clinical Science, 93: 257-263.

18. J aeger $P$, Portmann $L, J$ acquet $A F \&$
Burckhardt P (1985). Influence of the calcium content of the diet on the incidence of mild hyperoxaluria in idiopathic renal stone formers. American J oumal of $\mathrm{Ne}$ phrology, 5: 40-44.

19. Robertson WG \& Peacock M (1980). The cause of idiopathic calcium stone disease: hypercalciuria or hyperoxaluria? Nephron, 26: 105-110.

20. Gambaro G, Vincenti M, Marchini F, D'Angelo A \& Baggio B (1993). Abnormal urate transport in erythrocytes of patients with idiopathic calcium nephrolithiasis: a possible link with hyperuricosuria. Clinical Science, 85: 41-44.

21. Woolfson RG \& Mansell MA (1994). Hyperoxaluria and renal calculi. Postgraduate Medical J oumal, 70: 695-698.

22. Archer $H E$, Dormer $A E$, Scowen $E F \&$ Watts RWE (1957). Studies on the urinary excretion of oxalate by normal subjects. Clinical Science, 16: 405-411.

23. Hodgkinson A \& Williams A (1972). An improved colorimetric procedure for urine oxalate. Clinica Chimica Acta, 36: 127-132.

24. Cohanim M \& Yendt ER (1980). Reduction of urine oxalate during long-term thiazide therapy in patients with calcium urolithiasis. Investigative Urology, 18: 170-173.

25. Coe FL, Favus MJ, Crockett $T$, Strauss AL, Parks J H, Porat A, Gantt C \& Sherwood LM (1982). Effects of low-calcium diet on urine calcium excretion, parathyroid function and serum $1,25(\mathrm{OH})_{2} \mathrm{D}_{3}$ levels in patients with idiopathic hypercalciuria and in normal subjects. American J ournal of Medicine, 72: 25-32.

26. Bushinsky DA (1996). Genetic hypercalciuric stone forming rats. Seminars in $\mathrm{Ne}$ phrology, 16: 448-457.

27. Kim M, Sessler NE, Tembe V, Favus MJ \& Bushinsky DA (1993). Response of genetic hypercalciuric rats to a low calcium diet. Kidney International, 43: 189-196. 